TEIXEIRA, Alessandra Vanessa; BECKER, Luciana Rosa; LOPES, Manuela Grazziotin Teixeira. A aplicabilidade da teoria dos sistemas de Niklas Luhmann na fundamentação das decisões jurídicas. Revista Eletrônica Direito e Política, Programa de Pós-Graduação Stricto Sensu em Ciência Jurídica da UNIVALI, Itajaí, v.11, n.1, $1^{0}$ quadrimestre de 2016. Disponível em: www.univali.br/direitoepolitica - ISSN 1980-7791.

\title{
A aplicabilidade da teoria dos sistemas de Niklas Luhmann na fundamentação das decisões jurídicas
}

\author{
The applicability of the theory of Niklas Luhmann as grounds for legal \\ decisions
}

\author{
Alessandra Vanessa Teixeira ${ }^{1}$ \\ Luciana Rosa Becker ${ }^{2}$ \\ Manuela Grazziotin Teixeira Lopes ${ }^{3}$
}

\begin{abstract}
RESUMO
O presente artigo tem como objetivo analisar a teoria dos sistemas de Niklas Luhmann e a sua aplicabilidade nas decisões jurídicas. O Estado Democrático de Direito apresenta novas exigências à forma de justificação das decisões jurídicas. As decisões jurídicas se tornam peças fundamentais à concretização das garantias constitucionais. Algumas respostas a essas novas exigências podem ser encontradas na teoria de Niklas Luhmann, da qual pode-se entender que a decisão jurídica sempre constitui um ato criativo de desdobramento de paradoxos que, exatamente por isso, exige graus mais sofisticados de justificação.
\end{abstract}

PALAVRAS-CHAVE: Decisões Jurídicas; Niklas Luhmann; Sistemas Sociais; Teoria dos Sistemas.

\footnotetext{
1 Mestranda em Direito pela Universidade de Passo Fundo. Bolsista CAPES. Advogada. Graduada em Direito pela Universidade de Passo Fundo. Pós-Graduada em Direito Público pela Faculdade Meridional - IMED. E-mail: alessandra.sp@hotmail.com

${ }^{2}$ Mestranda em Direito pela Universidade de Passo Fundo. Graduada em Direito pela Universidade de Passo Fundo. Pós-graduanda em Direito do Trabalho e Processo do Trabalho pela Faculdade Meridional - IMED. E-mail: lucianarosabecker@hotmail.com

3 Mestranda em Direito pela Universidade de Passo Fundo. Bolsista UPF. Advogada. Graduada em Direito pela Universidade de Passo Fundo. Pós-Graduada em Direito Ambiental Internacional pela Universidade Federal do Rio Grande do Sul- UFRGS. Pós-graduanda do curso de Gestão Empresarial pela Escola de Administração da Universidade Federal do Rio Grande do Sul- UFRGS. E-mail: mgrazziotin@hotmail.com
} 
TEIXEIRA, Alessandra Vanessa; BECKER, Luciana Rosa; LOPES, Manuela Grazziotin Teixeira. A aplicabilidade da teoria dos sistemas de Niklas Luhmann na fundamentação das decisões jurídicas. Revista Eletrônica Direito e Política, Programa de Pós-Graduação Stricto Sensu em Ciência Jurídica da UNIVALI, Itajaí, v.11, n.1, $1^{0}$ quadrimestre de 2016. Disponível em: www.univali.br/direitoepolitica - ISSN 1980-7791.

\section{ABSTRACT}

This article aims to analyze the theory of Niklas Luhmann systems and their applicability in legal decisions. The democratic rule of law presents new demands on the form of justification of legal decisions. The legal decisions become fundamental parts the implementation of constitutional guarantees. Some answers to these new requirements can be found in the theory of Niklas Luhmann, which can be understood that the legal decision is always a creative act of unfolding paradoxes that exactly why, requires more sophisticated degrees of justification.

KEYWORDS: Legal Decisions; Niklas Luhmann; Social Systems; Systems Theory.

\section{INTRODUÇÃO}

Niklas Luhmann é considerado um dos mais importantes teóricos alemães na contemporaneidade. Sua contribuição mais significativa é a renovação da teoria dos sistemas, baseada numa mudança paradigmática fundamental: passar da distinção do todo e das partes, para a distinção de sistema e entorno, tendo como referência o conceito de complexidade.

Em Niklas Luhmann, podemos encontrar um tipo diferente de entendimento a respeito de como os juízes decidem. No âmbito da sua teoria dos sistemas sociais autopoiéticos, a investigação da decisão jurídica é realizada por meio de uma análise das operações de decisão como formas de distinção.

Nesse contexto, o presente artigo objetiva explanar acerca da teoria dos sistemas sociais de Luhmann, partindo de uma noção geral sobre os sistemas sociais, passando pelos conceitos de autopoiésis, autorreferência, comunicação, diferença sistema/entorno, para, finalmente, analisar a aplicabilidade e importância da referida teoria nas decisões jurídicas.

\section{A TEORIA DOS SISTEMAS DE NIKLAS LUHMANN: UMA BREVE EXPLANAÇÃO}

Na teoria de Luhmann a noção de sistema é central. A teoria dos sistemas vai muito além de ocupar-se com os sistemas em contraste com outros objetos, ela 
TEIXEIRA, Alessandra Vanessa; BECKER, Luciana Rosa; LOPES, Manuela Grazziotin Teixeira. A aplicabilidade da teoria dos sistemas de Niklas Luhmann na fundamentação das decisões jurídicas. Revista Eletrônica Direito e Política, Programa de Pós-Graduação Stricto Sensu em Ciência Jurídica da UNIVALI, Itajaí, v.11, n.1, $1^{0}$ quadrimestre de 2016. Disponível em: www.univali.br/direitoepolitica - ISSN 1980-7791.

ocupa-se com o mundo, visto sob a ótica da diferença, ou seja, a diferença entre sistema e entorno ${ }^{4}$ (ambiente). Logo, a teoria dos sistemas abrange tudo o que existe, limitando-se à condição de que seja indicado, sempre, se trata-se de sistema ou entorno (ambiente).$^{5}$

En primer lugar, Luhmann pretende que su teoría tenga un alcance general y que pueda aplicarse a diferentes dominios. La generalidad de la teoría es un compromiso constante en Luhmann, y hace que sus planteamientos no queden reducidos a determinados ámbitos particulares, sino que mantenga siempre una tensión de generalidad. Tal exigencia de generalidad convierta a la teoría en un verdadero artificio de generación de problemas que deben ser recogidos en su raíz general por la teoría. ${ }^{6}$

A intenção de Luhmann não era elaborar uma teoria específica a determinado âmbito social. A sua teoria pretende ser universal, capaz de abarcar tudo o que existe, revelando-se uma teoria geral da sociedade. Para dar conta disso, a teoria mostra-se complexa e abstrata e contém uma vasta terminologia. Existe um encadeamento de ideias que constroem uma estrutura aplicável à sociedade inteira.

La teoría de Luhmann tiene un punto de partida esencial que estriba en el reconocimiento de la complejidad y en exigir que toda teoría debe ser una arma para reducirla. Entiende Luhmann por complejidad la sobreabundancia de relaciones, de posibilidades, de conexiones, de modo que no sea posible plantear una correspondencia biunívoca y lineal de elemento con elemento. El problema esencial de nuestra sociedad es, precisamente, el aumento de su propia complejidad: lo que Luhmann denomina el aumento de la diferenciación de una sociedad. En forma paralela a ese aumento se precisa poseer instrumentos que permitan reducir la complejidad. ${ }^{7}$

4 Sobre essa diferenciação entre sistema e entorno (ambiente), será feita uma explanação no tópico seguinte, onde serão esclarecidos também alguns outros conceitos utilizados na teoria de Luhmann.

5 LUHMANN, Niklas. Novos desenvolvimentos na teoria dos sistemas. In: NEVES, Clarissa Eckert Baeta; SAMIOS, Eva Machado Barbosa (Org.). Niklas Luhmann: A nova teoria dos sistemas. Porto Alegre: Editora da Universidade/Goethe-Institut, 1997. p. 50.

6 LUHMANN, Niklas. Sociedad y sistema: la ambición de la teoría. Tradução Santiago López Petit e Dorothee Schmitz. Introdução Ignacio Izuzquiza. Barcelona: Ediciones Paidós Ibérica, 1990. p. 13.

${ }^{7}$ LUHMANN, Niklas. Sociedad y sistema: la ambición de la teoría. 1990. p. 16. 
TEIXEIRA, Alessandra Vanessa; BECKER, Luciana Rosa; LOPES, Manuela Grazziotin Teixeira. A aplicabilidade da teoria dos sistemas de Niklas Luhmann na fundamentação das decisões jurídicas. Revista Eletrônica Direito e Política, Programa de Pós-Graduação Stricto Sensu em Ciência Jurídica da UNIVALI, Itajaí, v.11, n.1, $1^{0}$ quadrimestre de 2016. Disponível em: www.univali.br/direitoepolitica - ISSN 1980-7791.

Um sistema pode ser chamado de complexo quando contém mais possibilidades do que pode realizar num dado momento. As possibilidades são tantas que o sistema vê-se obrigado a selecionar apenas algumas delas para poder continuar operando. O sistema não consegue dar conta de todas elas ao mesmo tempo, tornando-se complexo quando não consegue responder imediatamente a todas as relações entre os elementos e nem todas as suas possibilidades podem realizar-se.

Para melhor entender a complexidade, deve-se pensar, inicialmente, no número das possíveis relações, dos possíveis acontecimentos e dos possíveis processos, pois é a partir disso que se poderá compreender que cada organismo, máquina e formação social, possuem um meio que é mais complexo, o qual oferece mais possibilidades do que as que o sistema pode aceitar, processar ou legitimar. ${ }^{8}$

[...] la complejidad sólo podrá reducirse en tanto se dé una mayor complejidad. Sólo el aumento de complejidad puede llevar a una reducción de la complejidad. [...] De ahí que una teoría de la sociedad, concebida como un instrumento de reducción de la complejidad social sea, ella misma, inmensamente compleja y deba dar cuenta de la sobreabundancia de relaciones y posibilidades que caracteriza a la sociedad contemporánea. ${ }^{p}$

Logo, a tendência é de que num ambiente mais complexo o sistema também se torne mais complexo, ainda que não na mesma proporção, ou seja, ao mesmo tempo em que a complexidade do ambiente diminui, a sua aumenta internamente.

Um dos pontos fundamentais da teoria de Luhmann é que: ao tempo em que os subsistemas sociais constituem entornos uns para os outros, a estrutura de relações entre eles define a própria forma como a sociedade organiza suas comunicações. E o aumento da complexidade sistêmica é o elemento que promove a diferenciação da sociedade.

\footnotetext{
8 LUHMANN. Niklas. Introdução à Teoria dos Sistemas. Tradução de Ana Cristina Arantes Nasser. Petrópolis, RJ: Vozes, 2009. p. 184.

${ }^{9}$ LUHMANN, Niklas. Sociedad y sistema: la ambición de la teoría. 1990. p. 17.
} 
TEIXEIRA, Alessandra Vanessa; BECKER, Luciana Rosa; LOPES, Manuela Grazziotin Teixeira. A aplicabilidade da teoria dos sistemas de Niklas Luhmann na fundamentação das decisões jurídicas. Revista Eletrônica Direito e Política, Programa de Pós-Graduação Stricto Sensu em Ciência Jurídica da UNIVALI, Itajaí, v.11, n.1, 10 quadrimestre de 2016. Disponível em: www.univali.br/direitoepolitica - ISSN 1980-7791.

La comunicación es considerada por Luhmann como un proceso de selecciones, y su análisis debe partir de la improbabilidad de la comunicación que debe sortear multitud de obstáculos antes de producirse con éxito. Con ello, Luhmann resalta el valor que tiene la selección en el modo de comportamiento propio de un sistema social y cómo la selección, si está adecuadamente estructurada, contribuye a reducir eficazmente la complejidad. De fundamental importancia es precisar que la comunicación es propia de los sistemas sociales. Tan sólo la sociedad y los sistemas sociales comunican, sobre sí mismos y sobre los otros sistemas sociales, guardando los modos propios de la clausura que constituye su Autopoiésis. En este sentido, la sociedad se compone de comunicaciones y es el ámbito de todas las comunicaciones posibles. ${ }^{10}$

Então, toda e qualquer comunicação que possa existir é interna ao sistema social e, em última análise, à sociedade (sistema social global) que é formada de todos os sistemas sociais. Entre o sistema e o ambiente não há comunicação. No ambiente está tudo que não é comunicação, mas que pode servir de tema para a comunicação interna do sistema. A consciência, por exemplo, faz parte do entorno do sistema e é usada como substrato da comunicação.

[...] La sociedad no es ningún caso especial de la acción, lo que sucede es que en los sistemas sociales la acción se constituye por medio de la comunicación y de la atribución en una reducción de complejidad, como autosimplificación indispensable del sistema. En el nivel de la teoría general de sistemas se habla de una construcción "mutualista" o "dialógica". ${ }^{11}$

Os sujeitos da comunicação não são os sistemas psíquicos, como se está acostumado a pensar, mas os próprios sistemas sociais. É importante salientar que a comunicação pode ocorrer ainda que a informação selecionada não seja idêntica à informação emitida; a realidade objetiva da informação não é requisito para a comunicação. Importa apenas que seja selecionada uma informação.

La ambición de Luhmann estriba [...] en construir una teoría que permita observar de modo eficaz la compleja sociedad contemporánea. Su intento puede resumirse en la

\footnotetext{
${ }^{10}$ LUHMANN, Niklas. Sociedad y sistema: la ambición de la teoría. 1990. p. 26-27.

11 LUHMANN, Niklas. Sistemas sociales: lineamentos para una teoría general. Barcelona; México; Santafé de Bogotá: Anthropos; Universidad Iberoamericana; CEJA. 1998. p. 140.
} 
TEIXEIRA, Alessandra Vanessa; BECKER, Luciana Rosa; LOPES, Manuela Grazziotin Teixeira. A aplicabilidade da teoria dos sistemas de Niklas Luhmann na fundamentação das decisões jurídicas. Revista Eletrônica Direito e Política, Programa de Pós-Graduação Stricto Sensu em Ciência Jurídica da UNIVALI, Itajaí, v.11, n.1, $1^{0}$ quadrimestre de 2016. Disponível em: www.univali.br/direitoepolitica - ISSN 1980-7791.

elaboración de una teoría como instrumento de observación, con el fin de orientar posteriores selecciones y modos de actuación. [...] La ambición de Luhmann es siempre una ambición de observación. ${ }^{12}$

Percebe-se, então, que a teoria sistêmica de Luhmann enfatiza os sistemas autopoiéticos, ou seja, os sistemas vivos, psíquicos e sociais, sobretudo este último, uma vez que o intuito do autor foi o de elaborar uma teoria geral da sociedade. Esses três sistemas, além de autopoiéticos, são também autorreferentes e operacionalmente fechados.

\section{AUTOPOIÉSIS, AUTORREFERÊNCIA, COMUNICAÇÃO, SISTEMA/ENTORNO: ALGUNS CONCEITOS UTILIZADOS POR LUHMANN EM SUA PROPOSTA TEÓRICA}

Niklas Luhmann desenvolveu a chamada teoria dos sistemas sociais e com ela trouxe inúmeros conceitos que a incorporam. Para o autor, a sociedade é formada por vários subsistemas sociais com funções específicas. Nesse sentido,

Un sistema social es un sistema autorreferencial autopoiético, que constituye como diferencia con respecto a un entorno. Es además constitutivo de sentido. Sus operaciones y últimos elementos son comunicaciones. No existe un sistema social único, sino diversos sistemas sociales. Los sistemas sociales surgen por autocatálisis de los problemas de doble contingencia, que permiten afrontar a través de sus operaciones. ${ }^{13}$

Para Luhmann a sociedade se compõe por diversos sistemas sociais comunicativos, partindo do pressuposto de que a sociedade moderna é um sistema mundial de extrema complexidade, dentro do qual vários subsistemas geram condições para si próprios e para os outros ao seu redor. Logo, existem

\footnotetext{
12 LUHMANN, Niklas. Sociedad y sistema: la ambición de la teoría. 1990. p. 35.

13 CORSI, Giancarlo; ESPOSITO, Elena; BARALDI, Claudio. GLU: glosario sobre la teoría social de Niklas Luhmann. Traducción de Miguel Romero Pérez, Carlos Villalobos. México, DF: Antropos, 1996. p. 152.
} 
TEIXEIRA, Alessandra Vanessa; BECKER, Luciana Rosa; LOPES, Manuela Grazziotin Teixeira. A aplicabilidade da teoria dos sistemas de Niklas Luhmann na fundamentação das decisões jurídicas. Revista Eletrônica Direito e Política, Programa de Pós-Graduação Stricto Sensu em Ciência Jurídica da UNIVALI, Itajaí, v.11, n.1, 10 quadrimestre de 2016. Disponível em: www.univali.br/direitoepolitica - ISSN 1980-7791.

vários outros sistemas menores dentro do sistema social, como o político, econômico, religioso, etc. Todos fazem parte de um sistema macro, o social. ${ }^{14}$

[...] tudo o que funciona como unidade para um sistema (estruturas, elementos, mas também o próprio sistema e o ambiente do sistema) precisa ser produzido através do próprio sistema. Não há nenhuma importação de unidade (ou seja, também nenhuma importação de informação) num sistema e menos ainda uma exportação. Naturalmente o próprio sistema pode observar e descrever o mundo sob este pressuposto; mas isto é e permanece então sua própria realização. ${ }^{15}$

Percebe-se, então, que os sistemas não possuem, em suas origens, suas próprias estruturas, sendo obrigados a construí-las. Essa construção se dá no interior do próprio sistema, pois não é dado ao sistema criar operações que bem entender, mas somente aquelas que são permitidas de início. Com isso, surge o ponto principal da teoria de Luhmann: a autopoiésis.

\subsection{AUTOPOIÉSIS}

Autopoiésis é um termo de origem biológica, criado pelo biólogo chileno Humberto Maturana, para definir a organização dos organismos vivos. Para Maturana, um sistema vivo se caracteriza pela capacidade de produzir e reproduzir por si mesmo os elementos que o constituem. Logo, cada célula é um sistema auto-criado. ${ }^{16}$

Enquanto Maturana restringe o conceito da autopoiésis a sistemas vivos, Luhmann o amplia para todos os sistemas em que se pode observar um modo de

\footnotetext{
14 PAIM, Eline, Luque Teixeira. Luhmann: o direito como sistema autopoiético. Disponível em: http://www.conteudojuridico.com.br/artigo, luhmann-o-direito-como-sistemaautopoietico,50762.html. Acessado em 04 jul. 2015.

15 LUHMANN, Niklas. Sobre os fundamentos teórico-sistêmicos da teoria da sociedade. In: NEVES, Clarissa Eckert Baeta; SAMIOS, Eva Machado Barbosa (Org.). Niklas Luhmann: A nova teoria dos sistemas. Porto Alegre: Editora da Universidade/Goethe-Institut, 1997. p. 65-66.
}

16 CORSI, Giancarlo; ESPOSITO, Elena; BARALDI, Claudio. GLU: glosario sobre la teoría social de Niklas Luhmann. 1996. p. 31-32. 
TEIXEIRA, Alessandra Vanessa; BECKER, Luciana Rosa; LOPES, Manuela Grazziotin Teixeira. A aplicabilidade da teoria dos sistemas de Niklas Luhmann na fundamentação das decisões jurídicas. Revista Eletrônica Direito e Política, Programa de Pós-Graduação Stricto Sensu em Ciência Jurídica da UNIVALI, Itajaí, v.11, n.1, $1^{0}$ quadrimestre de 2016. Disponível em: www.univali.br/direitoepolitica - ISSN 1980-7791.

operação específico e exclusivo, que são, em sua opinião, os sistemas sociais e os sistemas psíquicos.

El concepto de autopoiesis constituye, sin lugar a dudas, una revolución conceptual. Pero su vuelco radical se sitúa exclusivamente en el plano de un principio teórico que obliga a compreender los sistemas a una profundidad hasta ahora no alcanzada por la teoría de sistemas. Sin embargo, su poder de aclaración deductiva es mínimo. Prácticamente lo único que afirma es que en el sistema existirán elementos y estructuras mientras se mantenga la autopoiesis. Pero el concepto no es capaz de aclarar qué tipos de estructuras deberán erigirse, ni aclarar tampoco el tipo de efectos causales que se puedan producir entre sistema y entorno. Dicho de manera nomológica: la revolución que introduce el concepto de autopoiesis como metaconcepto teórico es inversamente proporcional a su capacidade de explicación predictiva. ${ }^{17}$

Ainda, segundo Luhmann

La autopoiesis no supone forzosamente que no exista en el entorno del sistema este tipo de operaciones con las cuales el sistema se autorreproduce. En el entorno de los organismo vivos hay otros organismos vivos, en el entorno de conciencia hay otra conciencia. Pero en ambos casos, el proceso de reproducción propio del sistema sólo se puede aplicar internamente. No se puede emplear para conectar sistema y entorno, o sea, no se puede sacar provecho de otra vida o de otra conciencia para el propio sistema. ${ }^{18}$

Dizer que os sistemas sociais são autopoiéticos, portanto, significa que estes produzem seus próprios elementos, possibilitando a identificação do próprio sistema como unidade.

O conceito de autopoiésis desloca o princípio de autoreferência do nível estrutural para o nível operativo. De acordo com isso um sistema é constituído por elementos autoproduzidos - e por nada mais. Tudo o que opera no sistema como unidade -, mesmo que seja um último elemento, não mais passível de ser decomposto - é produzido no próprio sistema através da rede de tais elementos. Isto tem, como conseqüência lógica, a tese de

\footnotetext{
17 LUHMANN, Niklas. Sistemas sociales: lineamentos para una teoría general. 1998. p. 21.

18 LUHMANN, Niklas. Sociedad y sistema: la ambición de la teoría. 1990. p. 92.
} 
TEIXEIRA, Alessandra Vanessa; BECKER, Luciana Rosa; LOPES, Manuela Grazziotin Teixeira. A aplicabilidade da teoria dos sistemas de Niklas Luhmann na fundamentação das decisões jurídicas. Revista Eletrônica Direito e Política, Programa de Pós-Graduação Stricto Sensu em Ciência Jurídica da UNIVALI, Itajaí, v.11, n.1, 10 quadrimestre de 2016. Disponível em: www.univali.br/direitoepolitica - ISSN 1980-7791.

um fechamento operacional de tais sistemas. O ambiente não pode contribuir para nenhuma operação de reprodução do sistema. O sistema, obviamente, também não pode operar no seu ambiente. Conseqüentemente o sistema não pode - e isso, apesar de ser uma conseqüência lógica, surge como algo um pouco surpreendente - utilizar suas próprias operações para estabelecer contatos com seu ambiente. Todas as operações do sistema são operações exclusivamente internas. Todas as informações processadas são, exclusivamente, seleções produzidas internamente, a partir de um campo de diferenciação de possibilidades, delineado única e exclusivamente no interior. O ambiente não pode contribuir com nada para este processo. ${ }^{19}$

Nesse sentido e em sua descrição da sociedade, Luhmann esclarece que

Os sistemas autopoiéticos são aqueles que por si mesmos produzem não só suas estruturas, mas também os elementos dos que estão constituídos - no interior destes mesmos elementos. Os elementos sobre os que se alcançam os sistemas autopoiéticos (que vistos sob a perspectiva do tempo não são mais que operações) não têm existência independente (...). Os elementos são informações, são diferenças que no sistema fazem uma diferença. ${ }^{20}$

No entanto, o que exatamente se reproduz na autopoiésis? Para Luhmann, o elemento básico de reprodução no sistema social é o processo de comunicação. Os sistemas sociais são entendidos como sistemas comunicativos. Somente a comunicação é uma operação puramente social porque pressupõe o envolvimento de vários sistemas psíquicos sem que se possa atribuí-la exclusivamente a um ou outro destes sistemas: não pode haver comunicação individual. Dessa forma, não é o ser humano quem comunica, mas o sistema social, daí a ideia de uma comunicação e de uma "sociedade sem seres humanos". ${ }^{21}$

${ }^{19}$ LUHMANN, Niklas. Por que uma teoria dos sistemas? In: NEVES, Clarissa Eckert Baeta; SAMIOS, Eva Machado Barbosa (Org.). Niklas Luhmann: A nova teoria dos sistemas. Porto Alegre: Editora da Universidade/Goethe-Institut, 1997. p. 41.

${ }^{20}$ LUHMANN, Niklas. La sociedad de la sociedad. México: Herder, 2007. p. 44.

${ }^{21}$ MELO JÚNIOR, Luiz Cláudio Moreira. A teoria dos sistemas sociais em Niklas Luhmann. Disponível em: http://www.scielo.br/scielo.php?pid=S010269922013000300013\&script=sci_arttext. Acessado em: 05 de jul. 2015. 
TEIXEIRA, Alessandra Vanessa; BECKER, Luciana Rosa; LOPES, Manuela Grazziotin Teixeira. A aplicabilidade da teoria dos sistemas de Niklas Luhmann na fundamentação das decisões jurídicas. Revista Eletrônica Direito e Política, Programa de Pós-Graduação Stricto Sensu em Ciência Jurídica da UNIVALI, Itajaí, v.11, n.1, $1^{0}$ quadrimestre de 2016. Disponível em: www.univali.br/direitoepolitica - ISSN 1980-7791.

Compreende-se, diante do exposto, que o conceito de autopoiésis afirma que só existem elementos e estruturas no sistema na medida em que esta se mantém constante.

\subsection{AUTORREFERÊNCIA}

Luhman, em diferentes momentos, discute o conceito de autorreferência. Explica que autorreferência de um sistema constitui-se no fato de que aquilo que pode ser compreendido como elemento, parte, processo, interação de (ou em) um sistema está voltado, envolvido, inexoravelmente, consigo mesmo. Nas palavras de Luhmann: "o conceito de autorreferência designa a unidade do sistema consigo mesmo" 22

Segundo Luhmann, "el concepto de autorreferencia indica el echo de que existen sistemas que se refieren a sí mismos mediante cada una de sus operaciones. Se trata de sistemas (orgânicos, psíquicos y sociales) que pueden observar la realidade sólo mediante el autocontacto" ${ }^{\prime 23}$.

Nesse sentido, Luhmann refere que

Con el concepto de autorreferencia se designa la unidad, que presenta para si misma un elemento, un proceso, un sistema. "Para si misma", esto significa: independiente del modo de observación de otros. El concepto no sólo define sino que también contiene una afirmación sobre cosas, pues sostiene que la unidad únicamente se alcanza a través de una operación relacional; lo que, a su vez, implica que la unidad es algo que se debe construir y no preexiste como individuo, como sustancia, como idea de la propia operación. (p. 89).

O autor define mais amplamente sistemas autorreferentes da seguinte forma:

Pode-se denominar um sistema como auto-referente quando os elementos que o constituem estão integrados como

22 LUHMANN, Niklas. Complejidad y modernidad: de la unidad a la diferencia. Madrid: Trotta, 1998. p. 55.

23 CORSI, Giancarlo; ESPOSITO, Elena; BARALDI, Claudio. GLU: glosario sobre la teoría social de Niklas Luhmann. 1996. p. 35. 
TEIXEIRA, Alessandra Vanessa; BECKER, Luciana Rosa; LOPES, Manuela Grazziotin Teixeira. A aplicabilidade da teoria dos sistemas de Niklas Luhmann na fundamentação das decisões jurídicas. Revista Eletrônica Direito e Política, Programa de Pós-Graduação Stricto Sensu em Ciência Jurídica da UNIVALI, Itajaí, v.11, n.1, $1^{0}$ quadrimestre de 2016. Disponível em: www.univali.br/direitoepolitica - ISSN 1980-7791.

unidades de função e em todas as relações entre estes elementos corre paralelamente uma remissão à autoconstituição; dessa maneira se reproduz continuamente a autoconstituição. ${ }^{24}$

Disto decorre o entendimento quase obrigatório, de que a noção de sistema impõe a ideia de que ele não pode operar além dos limites que o constituem como tal, que o designam como unidade; isto é, não pode operar como se fossem capilares ou redes que se comunicam diretamente - relação causal (causa e efeito): contato, toque, contaminação. Todo o seu operar constitui-se numa "dobra" sobre si mesma, no sentido de que as etapas, os momentos dessa operação adotam uma circularidade que se auto-retro-alimenta. É importante, entretanto, entender que quando se fala em elementos, partes de um sistema, deve-se adotar uma postura cognitiva não analítica para uma melhor compreensão de um sistema como unidade autorreferenciada. ${ }^{25}$

Em síntese, pode-se verificar até o momento que os sistemas sociais são autorreferenciais porque são capazes de operar com base em suas próprias operações constituintes, são autopoiéticos porque se autorreproduzem ou produzem a si mesmos enquanto unidade sistêmica.

\subsection{COMUNICAÇÃO}

Niklas Luhmann dispõe de toda uma teoria social baseada na comunicação. Para o autor, a comunicação é a operação específica que identifica os sistemas sociais: não existe sistema social que não tenha como operação própria a comunicação e não existe comunicação fora dos sistemas sociais. Já que toda

\footnotetext{
${ }^{24}$ LUHMANN, Niklas. Complejidad y modernidad: de la unidad a la diferencia. 1998. p. 56.

25 RODRIGUES, Léo Peixoto. Sistemas auto-referentes, autopoiéticos: noções-chave para a compreensão de Niklas Luhmann. Disponível em: http://pensamentoplural.ufpel.edu.br/edicoes/03/05.pdf. Acessado em: 10 jul. 2015
} 
TEIXEIRA, Alessandra Vanessa; BECKER, Luciana Rosa; LOPES, Manuela Grazziotin Teixeira. A aplicabilidade da teoria dos sistemas de Niklas Luhmann na fundamentação das decisões jurídicas. Revista Eletrônica Direito e Política, Programa de Pós-Graduação Stricto Sensu em Ciência Jurídica da UNIVALI, Itajaí, v.11, n.1, 10 quadrimestre de 2016. Disponível em: www.univali.br/direitoepolitica - ISSN 1980-7791.

comunicaçao é uma operação interna de um sistema social, entre os sistemas sociais e seu entorno não existe comunicação. ${ }^{26}$

O autor refere que

En la teoría de sistemas lo que se enfatiza es la verdadera emergencia de la comunicación. No existe propiamente transmisión de alguna cosa; lo que hay es más bien una redundancia creada en el sentido de que la comunicación inventa su propia memoria que puede ser evocada por distintas personas, de diferentes maneras. Cuando $A$ comunica algo a $B$, la comunicación siguiente puede dirigirse no mismo a $A$ que a $B$. Se puede imaginar, entonces, el sistema como un pulsar constante: con cada creación de redundancia y con cada selección el sistema se expande y recontrae permanentemente. ${ }^{27}$

A comunicação seria a base de emergência das relações humanas. Esta premissa do pensamento luhmaniano extrapola o âmbito das comunicações interpessoais, em que se destacam as particularidades da interação face a face, e se manifesta na própria formação das estruturas da sociedade. Isso porque a teoria está fundamentalmente assentada na ideia de que os processos civilizatórios se fazem a partir de atos comunicativos. Significa dizer que os diversos sistemas sociais que conhecemos hoje, e que compõem a estrutura da organização social - isto é, a política, a economia, o direito, a religião, a educação, etc. -, se formaram e são regulados pela comunicação. Ao longo do tempo, conforme as mensagens enunciadas foram aceitas ou rejeitadas, a sociedade teria se tornado complexa, formando, por seleção, sistemas diferenciados. ${ }^{28}$

La teoría de sistemas reemplaza la comprensión directa del consenso con otro argumento: la comunicación conduce a la decisión de que tanto la información como el acto de comunicar pueden ser aceptados o rechazados. Un mensaje

${ }^{26}$ CORSI, Giancarlo; ESPOSITO, Elena; BARALDI, Claudio. GLU: glosario sobre la teoría social de Niklas Luhmann. 1996. p. 47.

27 LUHMANN, Niklas. Introducción a la teoría de sistemas. México: Universidad Iberoamericana, 2002. p. 308.

28 QUIROGA, Tiago; TORT, Paulliny Gualberto. Contribuições teóricas de Niklas Luhmann: a improbabilidade da comunicação e os meios simbolicamente generalizados. In: Conexão Comunicação e Cultura, UCS, Caxias do Sul - v. 12, n. 24, jul./dez. 2013. Disponível em: http://www.ucs.br/etc/revistas/index.php/conexao/article/viewFile/2365/1534. Acessado em 10 jul. 2015. 
TEIXEIRA, Alessandra Vanessa; BECKER, Luciana Rosa; LOPES, Manuela Grazziotin Teixeira. A aplicabilidade da teoria dos sistemas de Niklas Luhmann na fundamentação das decisões jurídicas. Revista Eletrônica Direito e Política, Programa de Pós-Graduação Stricto Sensu em Ciência Jurídica da UNIVALI, Itajaí, v.11, n.1, 10 quadrimestre de 2016. Disponível em: www.univali.br/direitoepolitica - ISSN 1980-7791.

es aceptado o no lo es. Esta es la primera alternativa creada por la comunicación y con ella emerge el riesgo de la no aceptación. Obliga a tomar una decisión que sólo se hace posible debido a la comunicación misma. En este sentido toda comunicación lleva implícito el riesgo Este riesgo, que está en la base de la comunicación, es un factor morfogenético de una relevancia muy alta, porque debido a eso surgirán, después, instrucciones que garanticen la aceptación aun en el caso de que una comunicación sea muy improbable. ${ }^{29}$

Nesse sentido, a sociedade teria evoluído graças à seletividade inerente à linguagem, que sempre dá ao interlocutor a possibilidade de aceitar ou rejeitar determinada mensagem, o que incide diretamente sobre as chances de essa mensagem ser passada adiante.

Luhmann afirmava que, de modo geral, toda mensagem se defronta com limites que tornam o sucesso comunicativo incerto. Esses limites seriam as improbabilidades da comunicação. Logo, de acordo com a teoria, o processo de evolução sociocultural é uma função da comunicação, na medida em que esta exerce um papel de filtragem dos conteúdos. As improbabilidades funcionariam assim como filtros selecionadores, através dos quais as mensagens exitosas criaram - e criam - as estruturas sociais existentes. ${ }^{30}$

No entanto, para Luhmann, a comunicação pode ser vista como um problema. Para uma teoria da comunicação "a comunicação é improvável", ou seja,

Em primeiro lugar, é improvável que alguém compreenda o que o outro quer dizer, tendo em conta o isolamento e a individualização da sua consciência. O sentido só se pode entender em função do contexto, e para cada um o contexto é, basicamente, o que a sua memória Ihe faculta.

A segunda improbabilidade é a de aceder aos receptores. É improvável que uma comunicação chegue a mais pessoas do

\footnotetext{
29 LUHMANN, Niklas. Introducción a la teoría de sistemas. 2002. p. 312.

30 QUIROGA, Tiago; TORT, Paulliny Gualberto. Contribuições teóricas de Niklas Luhmann: a improbabilidade da comunicação e os meios simbolicamente generalizados. In: Conexão Comunicação e Cultura, UCS, Caxias do Sul - v. 12, n. 24, jul./dez. 2013. Disponível em: http://www.ucs.br/etc/revistas/index.php/conexao/article/viewFile/2365/1534. Acessado em 10 jul. 2015.
} 
TEIXEIRA, Alessandra Vanessa; BECKER, Luciana Rosa; LOPES, Manuela Grazziotin Teixeira. A aplicabilidade da teoria dos sistemas de Niklas Luhmann na fundamentação das decisões jurídicas. Revista Eletrônica Direito e Política, Programa de Pós-Graduação Stricto Sensu em Ciência Jurídica da UNIVALI, Itajaí, v.11, n.1, $1^{0}$ quadrimestre de 2016. Disponível em: www.univali.br/direitoepolitica - ISSN 1980-7791.

que as que se encontram presentes numa situação dada. $\mathrm{O}$ problema assenta na extensão espacial e temporal.

$[\ldots]$

A terceira improbabilidade é a de obter o resultado desejado. Nem sequer o facto de que uma comunicação tenha sido entendida garante que tenha sido também aceite. Por "resultado desejado" entendo o facto de que o receptor adopte o conteúdo selectivo da comunicação (a informação) como premissa do seu próprio comportamento, incorporando à seleção novas selecções e elevando assim o grau de selectividade. $^{31}$

Mais que simples dificuldades a vencer, as improbabilidades da comunicação se configuram conceitualmente como verdadeiros entraves ao êxito das mensagens, fazendo com que as chances de rechaço dos conteúdos sejam sempre maiores que as de aceitação. Nesse ponto, encontramos o cerne da teoria luhmaniana: para o autor, toda comunicação é improvável. De acordo com Luhmann, a comunicação é improvável a despeito de a vivenciarmos cotidianamente e de dispormos de todo um aparato tecnológico que a facilite ao desdobrar nossas relações no tempo e no espaço. ${ }^{32}$

\subsection{SISTEMA X ENTORNO}

A diferença entre sistema e entorno é fundamental para o entendimento da teoria dos sistemas sociais de Luhmann. Nesse sentido,

La diferencia sistema/entorno es el punto de partida del planteamiento de la teoría de los sistemas de Luhmann. Um sistema no puede darse independentemente de su entorno, em cuanto que se constituye precisamente al trazar, mediante sus operaciones, um límite que lo distingue de lo

\footnotetext{
31 LUHMANN, Niklas. A Improbabilidade da Comunicação. Tradução de Anabela Carvalho. Lisboa: Vega, 2006. p. 42-43.

32 QUIROGA, Tiago; TORT, Paulliny Gualberto. Contribuições teóricas de Niklas Luhmann: a improbabilidade da comunicação e os meios simbolicamente generalizados. In: Conexão Comunicação e Cultura, UCS, Caxias do Sul - v. 12, n. 24, jul./dez. 2013. Disponível em: http://www.ucs.br/etc/revistas/index.php/conexao/article/viewFile/2365/1534. Acessado em 10 jul. 2015.
} 
TEIXEIRA, Alessandra Vanessa; BECKER, Luciana Rosa; LOPES, Manuela Grazziotin Teixeira. A aplicabilidade da teoria dos sistemas de Niklas Luhmann na fundamentação das decisões jurídicas. Revista Eletrônica Direito e Política, Programa de Pós-Graduação Stricto Sensu em Ciência Jurídica da UNIVALI, Itajaí, v.11, n.1, $1^{0}$ quadrimestre de 2016. Disponível em: www.univali.br/direitoepolitica - ISSN 1980-7791.

que como ambiente, no le pertence. Ningún sistema puede operar fuera de sus límites: sin un entorno del cual distinguirse no sería posible identificar un sistema, un ámbito autónomo en el que rigen condiciones específicas, que se sustrae a una coincidencia punto por punto con los estados del entorno. ${ }^{33}$

A diferenciação entre sistema e entorno, por sua vez, realça que tudo aquilo que não diz respeito ao sistema observado é tido como entorno, até mesmo os diferentes tipos de sistemas que coexistem em uma mesma dimensão espaçotemporal. Com isso, o sistema social se distingue de tudo o mais, inclusive dos seres humanos. Na medida em que o sistema social e o sistema psíquico operam de forma autopoiética e de forma separada, a sociedade é tida como entorno para o indivíduo: os seres humanos são o entorno psíquico dos sistemas sociais.

[...] el punto de partida de cualquier análisis sistémicoteórico tiene que ser la diferencia entre sistema y entorno. Los sistemas no sólo se orientan ocasionalmente o por adaptación hacia su entorno, sino de manera estructural, y no podrían existir sin el entorno. Se constituyen y se mantienen a través de la producción y el mantenimiento de una diferencia respecto al entorno, y utilizan sus límites para regular esta diferencia. Sin la diferencia ni siquiera existiría la autorreferencia, pues la diferencia es la premisa para la función de las operaciones autorreferenciales. En este sentido, el mantenimiento del límite (boundary maintence) significa el mantenimiento del sistema. ${ }^{34}$

A diferença resultante entre a diferença sistema/entorno é a unidade que caracteriza o próprio sistema. O sistema, nesse sentido, não passa da repetição da diferença do próprio sistema com relação ao seu entorno.

[...] la diferencia entre sistema y entorno obliga a sustituir la diferencia entre todo y parte por una teoría de la diferenciación sistémica. La diferenciación sistémica no es más que una repetición de la constitución de sistemas en el interior de sistemas. Dentro de los sistemas se puede dar una posterior diferenciación de otras diferencias sistema/entorno. El sistema gana así la función de "medio interno" para los subsistemas, o sea que para cada

\footnotetext{
${ }^{33}$ CORSI, Giancarlo; ESPOSITO, Elena; BARALDI, Claudio. GLU: glosario sobre la teoría social de Niklas Luhmann. 1996. p. 148.
}

34 LUHMANN, Niklas. Sociedad y sistema: la ambición de la teoría. 1990. p. 50-51. 
TEIXEIRA, Alessandra Vanessa; BECKER, Luciana Rosa; LOPES, Manuela Grazziotin Teixeira. A aplicabilidade da teoria dos sistemas de Niklas Luhmann na fundamentação das decisões jurídicas. Revista Eletrônica Direito e Política, Programa de Pós-Graduação Stricto Sensu em Ciência Jurídica da UNIVALI, Itajaí, v.11, n.1, $1^{0}$ quadrimestre de 2016. Disponível em: www.univali.br/direitoepolitica - ISSN 1980-7791.

subsistema se da de un modo específico. De esta manera, la diferencia sistema/entorno se reduplica, y el sistema en su conjunto de automultiplica como una multiplicidad de diferencias internas sistema/entorno. Cada diferencia entre subsistema y entorno interno reconstituye el sistema en su conjunto, pero siempre desde una perspectiva diferente. La diferenciación sistémica es, por tanto, un procedimiento para aumentar la complejidad. ${ }^{35}$

Sistema e entorno são mutuamente condicionados, na medida em que a existência de um sempre pressupõe a do outro. Contudo, o entorno não é estruturalmente organizado como o sistema. Nele vige uma complexidade maior que dentro do sistema. Portanto, alerta Luhmann que o entorno não é nenhum sistema, ainda que ele alcance sua unidade somente mediante o sistema e sempre em relação com o sistema.

\section{A TEORIA DOS SISTEMAS SOCIAIS COMO FUNDAMENTO PARA AS DECISÕES JURÍDICAS}

Inicialmente, é importante esclarecer o conceito de direito na teoria dos sistemas sociais de Luhmann, para que se possa compreender a possibilidade de sua aplicação na fundamentação das decisões jurídicas.

El derecho es um sistema funcionalmente diferenciado de la sociedade moderna, cuya función es mantener estables las expectativas aun em caso de que resulten vanas. Dichas expectativas son normas que permanecen estables independentemente de su eventual violación. El código que orienta el derecho está constituido por la diferencia binaria legal/ilegal: existe comunicación jurídica toda vez que en caso de controvérsias alguien reivindica los derechos y en referencia a la normatividade vigente debe lograr decidir quién pose ela razón de la legalidade y quién no. Por lo tanto, el derecho es un sistema que resuelve los conflitos, y al mismo tempo genera otros, ya que con base en el derecho puede resistirse a las pressiones o pueden rechazarse las órdenes expresas. ${ }^{36}$

\footnotetext{
35 LUHMANN, Niklas. Sociedad y sistema: la ambición de la teoría. 1990. p. 53-54.

${ }^{36}$ CORSI, Giancarlo; ESPOSITO, Elena; BARALDI, Claudio. GLU: glosario sobre la teoría social de Niklas Luhmann. 1996. p. 54.
} 
TEIXEIRA, Alessandra Vanessa; BECKER, Luciana Rosa; LOPES, Manuela Grazziotin Teixeira. A aplicabilidade da teoria dos sistemas de Niklas Luhmann na fundamentação das decisões jurídicas. Revista Eletrônica Direito e Política, Programa de Pós-Graduação Stricto Sensu em Ciência Jurídica da UNIVALI, Itajaí, v.11, n.1, $1^{0}$ quadrimestre de 2016. Disponível em: www.univali.br/direitoepolitica - ISSN 1980-7791.

O direito é uma decisão que tem poder para se impor, é uma decisão com força. Toda a decisão não é puramente jurídica, ela tem um pouco de sociedade. Falar em decisão é falar em inserção social.

[...] a estrutura de um sistema social tem por função regular a complexidade do sistema. Em última análise a complexidade de um sistema é sempre a complexidade estruturalmente possibilitada (contingente), mas por outro lado também a estrutura do sistema depende de sua complexidade, pois improváveis estruturas arriscadas, como a mutabilidade legal do direito, já pressupõem uma alta complexidade do sistema. Sistemas simples tem necessidades estruturais diferentes de sistemas mais complexos, mas também possuem menos possibilidades de erigir e manter estruturas relevantes enquanto pressupostos de outras possibilidades estruturais. Sociedades simples, por exemplo, possuem um direito tradicionalmente determinado, concebido em termos relativamente concretos. No decorrer do desenvolvimento social em direção à complexidade mais elevada, o direito tem que abstrair-se crescentemente, tem que adquirir uma elasticidade conceitual-interpretativa para abranger situações heterogêneas, tem que ser modificável através de decisões, ou seja: tem que tornar-se direito positivo. Nesse sentido formas estruturais e graus de complexidade da sociedade condicionam-se reciprocamente. ${ }^{37}$

Para Luhmann a grande questão é a decisão e o problema da decisão é a complexidade, o excesso de possibilidade de fazer, pois é muito difícil tomar uma decisão correta devido ao excesso de possibilidades. Já o grande problema da complexidade é a frustração, pois também há o fator de que há outras pessoas e outras expectativas que se cruzam.

Nesse sentido, importante fazer uma análise referente ao caso do aborto de fetos anencéfalos, o qual apresenta decisões do STF envolvendo a possibilidade da aplicação da teoria sistêmica de Luhmann.

Sabe-se que no Brasil o aborto é crime, disposto no artigo 124 e 125 CP, o qual prevê a detenção em caso de aborto com o consentimento da mulher.

37 LUHMANN, Niklas. Sociologia do Direito. v.I. Tradução Gustavo Bayer. Rio de Janeiro: Tempo Brasileiro, 1983. p. 15. 
TEIXEIRA, Alessandra Vanessa; BECKER, Luciana Rosa; LOPES, Manuela Grazziotin Teixeira. A aplicabilidade da teoria dos sistemas de Niklas Luhmann na fundamentação das decisões jurídicas. Revista Eletrônica Direito e Política, Programa de Pós-Graduação Stricto Sensu em Ciência Jurídica da UNIVALI, Itajaí, v.11, n.1, $1^{0}$ quadrimestre de 2016. Disponível em: www.univali.br/direitoepolitica - ISSN 1980-7791.

Entretanto, no dia 12 de abril de 2012, o plenário do Supremo Tribunal Federal decidiu não qualificar como crime o aborto de feto anencéfalo.

O Código Penal prevê três situações que descaracteriza o suposto crime, são elas: quando praticado por médico capacitado; quando há risco de vida para a mulher causado pela gravidez; quando a gravidez é resultante de um estupro; e, desde 2012, pela decisão do STF através da ADPF 54, agora também para feto anencéfalo.

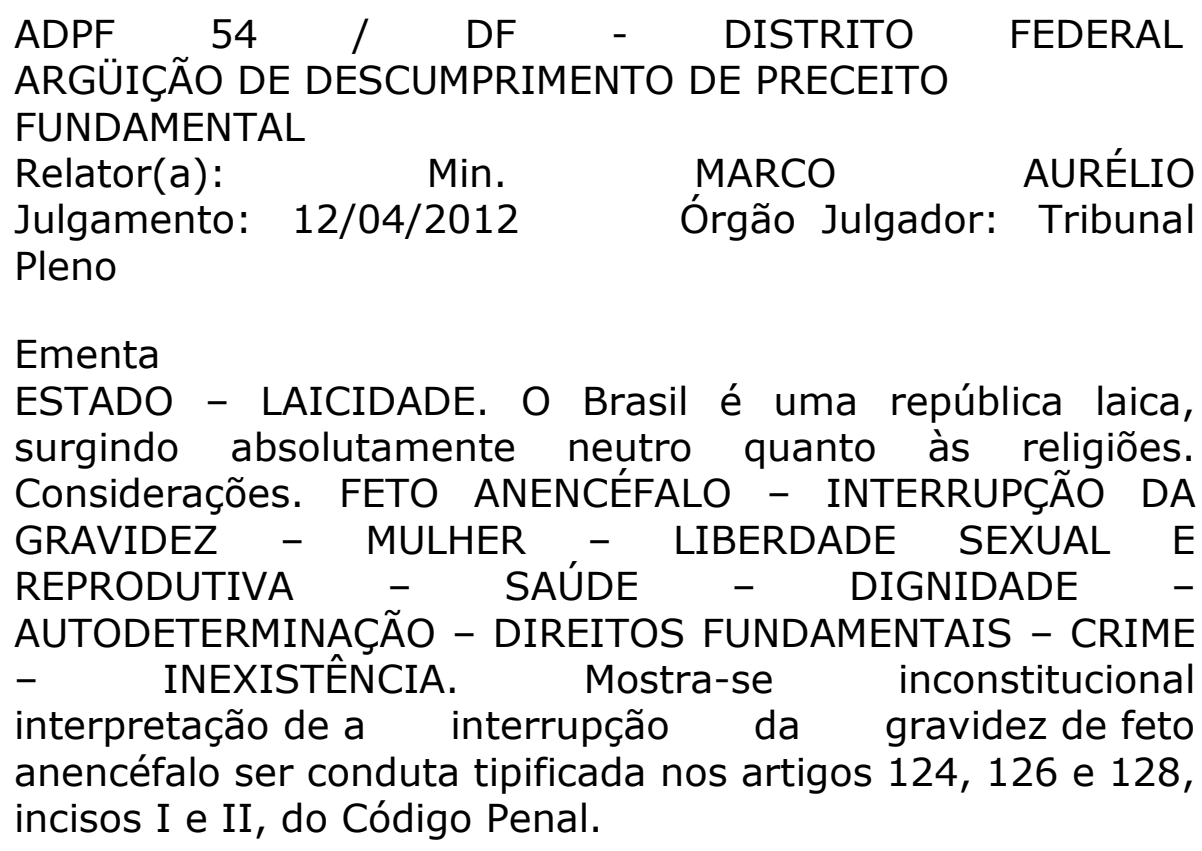

Esta decisão tornou-se conhecida e distinta das demais, pois passou por cima de conceitos religiosos e jurídicos, uma vez que mostrou até que ponto o direito pode alcançar na vida das pessoas.

Fez-se uma análise da situação e das questões sociais que envolvem a anencefalia e o aborto, ponderou-se questões, tais como: risco da gravidez para a mãe; curta inexistência de vida do feto, e etc., até que o STF decidisse a favor do aborto em casos de anencefalia.

Nessas questões envolvendo direito e moral, pode-se encaixar o pensamento de Luhmann que, em sua teoria sistêmica, refere que direito e moral são sistemas distintos, os quais embora sejam autopoiéticos, são também ligados entre si. 
TEIXEIRA, Alessandra Vanessa; BECKER, Luciana Rosa; LOPES, Manuela Grazziotin Teixeira. A aplicabilidade da teoria dos sistemas de Niklas Luhmann na fundamentação das decisões jurídicas. Revista Eletrônica Direito e Política, Programa de Pós-Graduação Stricto Sensu em Ciência Jurídica da UNIVALI, Itajaí, v.11, n.1, $1^{0}$ quadrimestre de 2016. Disponível em: www.univali.br/direitoepolitica - ISSN 1980-7791.

Então, mesmo que o direito e a moral formem sistemas distintos, a moral é aliada ao direito no seu processo de positivação, pois é a moral quem determina quais os bens que serão juridicamente tutelados. Dentro da teoria de Luhmann, o juiz pode utilizar-se de valores morais, mas sua decisão sempre deve estar de acordo com o texto constitucional.

No Brasil, a intervenção do direito no caso em questão, emergiu à medida que os índices de anencefalia se tornaram corriqueiros, a ponto de tornar-se um conflito do aborto ou não de um feto anencéfalo, obrigando a levantar diversas questões, as quais dizem respeito ao direito da mãe e do feto.

Nas decisões dos ministros do STF, é possível pensar na teoria de Luhmann, pois ao resolver os casos, os mesmos buscam fazer uma análise da norma, de forma a adequá-las aos princípios morais.

Verifica-se que se faz uma análise das leis, de forma a procurar interpretações distintas das comuns, e especialmente em casos onde podem ser vistos direitos em conflito direto, busca-se a ponderação de qual tem mais valor e, qual possa ser menos nocivo, mais uma vez, tendo em vista o feto e a mãe.

Nesse caso, é fácil visualizar a teoria sistêmica de Luhmann, objeto de análise, tendo em vista que os ministros buscaram a melhor solução, mesmo indo contra a tradição, haja vista, os anseios da sociedade por essa decisão.

Por isso, é necessário analisar a peculiaridade de cada caso, de modo que se possa fazer diferentes leituras e questionamentos das decisões com o objetivo de chegar a uma única resposta correta.

Assim, tendo em vista a decisão do Supremo Tribunal Federal (STF), que por maioria, decidiu por desclassificar como crime o aborto de fetos anencéfalos é possível visualizar a teoria em questão e a evolução positiva do direito frente às necessidades da sociedade.

Para Luhmann, a política e o direito são sistemas distintos que não se confundem, ou seja, as decisões judiciais são jurídicas e não políticas. Assim, o direito positivo moderno que é estabelecido e validado a partir de decisões, 
TEIXEIRA, Alessandra Vanessa; BECKER, Luciana Rosa; LOPES, Manuela Grazziotin Teixeira. A aplicabilidade da teoria dos sistemas de Niklas Luhmann na fundamentação das decisões jurídicas. Revista Eletrônica Direito e Política, Programa de Pós-Graduação Stricto Sensu em Ciência Jurídica da UNIVALI, Itajaí, v.11, n.1, $1^{0}$ quadrimestre de 2016. Disponível em: www.univali.br/direitoepolitica - ISSN 1980-7791.

busca legitimidade com os valores ou princípios no momento que mantém a coerência dos sistemas tendo em vista decisões proferidas em outros casos, pois assim representam a vontade da sociedade.

A legitimidade toma um caminho diferente, pois Luhmann caracteriza como "conceitos jurídicos indefinidos", reconhecendo como parte de uma evolução do Direito que obriga a necessidade de uma decisão judicial fundamentada nos critérios jurídicos, que remete à legislação competente, e também a todo um universo de formação. ${ }^{38}$

Dentro dessa perspectiva, o direito deve ter uma atuação direta sobre os demais elementos estranhos ao seu próprio sistema, haja vista, necessitar de uma consistência jurídica, formada por princípios fundamentais e sociológicos como expõe Luhmann: "El problema de los 'hard cases' ya existía antes del proceso de diferenciación del sistema del derecho. Entonces estos casos difíciles"39

O argumento de Luhmann afirma que os tribunais estariam bem ao centro do sistema do Direito, sendo que as relevâncias, preocupações e conflitos já não seriam os mesmos, urgindo na necessidade de decidir conflitos e aplicar a justiça.

Que los tribunales se vean en la necesidad de decidir es el punto de partida para construcción del universo jurídico, para el pensamiento jurídico y para la argumentación jurídica. Por eso la legitimación, en el sentido de relación con valores que transcienden el derecho no juega un papel importante. Por eso, todo depende de que las decisiones anteriores que orientan perduren: salvo que se las cambie. Por eso, la res iudicata es intocable, a no ser que se apliquen reglas excepcionales previstas por el derecho. Y, por eso, el derecho debe como un universo cerrado en sí mismo en el que, aun bajo tensiones sociales extremas, se puede practicar la "argumentación puramente jurídica" que decide por sí misma los espacios de interpretación que se pueden

\footnotetext{
38 LUHMANN, Niklas. El derecho de la sociedad. Tradução: Javier Torres Nafarrete. México: Universidad Iberoamericana, 2006. p. 341.

39 LUHMANN, Niklas. El derecho de la sociedad. 2006. p. 375.
} 
TEIXEIRA, Alessandra Vanessa; BECKER, Luciana Rosa; LOPES, Manuela Grazziotin Teixeira. A aplicabilidade da teoria dos sistemas de Niklas Luhmann na fundamentação das decisões jurídicas. Revista Eletrônica Direito e Política, Programa de Pós-Graduação Stricto Sensu em Ciência Jurídica da UNIVALI, Itajaí, v.11, n.1, $1^{0}$ quadrimestre de 2016. Disponível em: www.univali.br/direitoepolitica - ISSN 1980-7791.

permitir, y en el que se puede rechazar la deformación pretendida. ${ }^{40}$

Diante de todo o enunciado, percebe-se a importância da Teoria Sistêmica de Niklas Luhmann para a sociedade, tanto para a formação de um novo pensamento, quanto e principalmente nas decisões jurídicas de questões polêmicas de difícil resolução, que se apresentam na sociedade contemporânea.

O fundamento da teoria, atrelado a sua efetiva aplicação, resulta em decisões bem fundamentadas e atualmente importantes para a resolução dos conflitos, uma vez que servem para auxiliar no esclarecimento e no refinamento das análises do fenômeno jurídico e assim contribuir no aperfeiçoamento de sua compreensão e resolução, de acordo com os anseios da sociedade.

\section{CONSIDERAÇÕES FINAIS}

Por meio da Teoria dos Sistemas de Luhmann, pode-se entender que a decisão jurídica sempre constitui um ato criativo de desdobramento de paradoxos que, exatamente por esse motivo, exige graus mais sofisticados de justificação.

A partir de Luhmann, percebe-se que direito e política são subsistemas sociais autopoiéticos, cada um se reproduzindo a partir de seus códigos próprios que permite que haja comunicação entre aqueles sistemas, de tal forma que ambos podem prestar serviços mútuos um ao outro, sem, contudo, perderem suas respectivas identidades.

Para Luhmann, o mais importante para se entender as decisões jurídicas na sociedade contemporânea é observar a diferença, a produção da diferença, os processos de produção das diferenças.

No contexto dos ideais políticos e normativos do Estado Democrático de Direito, tem-se que esperar, portanto, que as decisões jurídicas levem à sério os valores e princípios constitucionais atualmente importantes para a sociedade. Não que o

\footnotetext{
40 LUHMANN, Niklas. El derecho de la sociedad. 2006. p. 379.
} 
TEIXEIRA, Alessandra Vanessa; BECKER, Luciana Rosa; LOPES, Manuela Grazziotin Teixeira. A aplicabilidade da teoria dos sistemas de Niklas Luhmann na fundamentação das decisões jurídicas. Revista Eletrônica Direito e Política, Programa de Pós-Graduação Stricto Sensu em Ciência Jurídica da UNIVALI, Itajaí, v.11, n.1, $1^{0}$ quadrimestre de 2016. Disponível em: www.univali.br/direitoepolitica - ISSN 1980-7791.

direito possa efetivamente substituir a política na concretização dos objetivos políticos do Estado Democrático de Direito, mas que pelo menos as decisões jurídicas possam criar diferenças no sentido desses ideais.

\section{REFERÊNCIAS DAS FONTES CITADAS}

CORSI, Giancarlo; ESPOSITO, Elena; BARALDI, Claudio. GLU: glosario sobre la teoría social de Niklas Luhmann. Traducción de Miguel Romero Pérez, Carlos Villalobos. México, DF: Antropos, 1996.

LUHMANN, Niklas. A Improbabilidade da Comunicação. Tradução de Anabela Carvalho. Lisboa: Vega, 2006.

Trotta, 1998.

Complejidad y modernidad: de la unidad a la diferencia. Madrid:

El derecho de la sociedad. Tradução: Javier Torres Nafarrete. México: Universidad Iberoamericana, 2006.

Introdução à Teoria dos Sistemas. Tradução de Ana Cristina Arantes Nasser. Petrópolis, RJ: Vozes, 2009.

La sociedad de la sociedad. México: Herder, 2007.

- Novos desenvolvimentos na teoria dos sistemas. In: NEVES, Clarissa Eckert Baeta; SAMIOS, Eva Machado Barbosa (Org.). Niklas Luhmann: A nova teoria dos sistemas. Porto Alegre: Editora da Universidade/Goethe-Institut, 1997.

Por que uma teoria dos sistemas? In: NEVES, Clarissa Eckert Baeta; SAMIOS, Eva Machado Barbosa (Org.). Niklas Luhmann: A nova teoria dos sistemas. Porto Alegre: Editora da Universidade/Goethe-Institut, 1997.

Sistemas sociales: lineamentos para una teoría general. Barcelona; México; Santafé de Bogotá: Anthropos; Universidad Iberoamericana; CEJA. 1998.

. Sobre os fundamentos teórico-sistêmicos da teoria da sociedade. In: NEVES, Clarissa Eckert Baeta; SAMIOS, Eva Machado Barbosa (Org.). Niklas Luhmann: A nova teoria dos sistemas. Porto Alegre: Editora da Universidade/Goethe-Institut, 1997.

Sociedad y sistema: la ambición de la teoría. Tradução Santiago López Petit e Dorothee Schmitz. Introdução Ignacio Izuzquiza. Barcelona: Ediciones Paidós Ibérica, 1990. 
TEIXEIRA, Alessandra Vanessa; BECKER, Luciana Rosa; LOPES, Manuela Grazziotin Teixeira. A aplicabilidade da teoria dos sistemas de Niklas Luhmann na fundamentação das decisões jurídicas. Revista Eletrônica Direito e Política, Programa de Pós-Graduação Stricto Sensu em Ciência Jurídica da UNIVALI, Itajaí, v.11, n.1, $1^{0}$ quadrimestre de 2016. Disponível em: www.univali.br/direitoepolitica - ISSN 1980-7791.

Sociologia do Direito. v.I. Tradução Gustavo Bayer. Rio de Janeiro: Tempo Brasileiro, 1983.

MELO JÚNIOR, Luiz Cláudio Moreira. A teoria dos sistemas sociais em Niklas Luhmann. Disponível em: http://www.scielo.br/scielo.php?pid=S010269922013000300013\&script=sci_arttext. Acessado em: 05 de jul. 2015.

PAIM, Eline, Luque Teixeira. Luhmann: o direito como sistema autopoiético. Disponível em: http://www.conteudojuridico.com.br/artigo,luhmann-o-direitocomo-sistema-autopoietico,50762.html. Acessado em 04 jul. 2015.

QUIROGA, Tiago; TORT, Paulliny Gualberto. Contribuições teóricas de Niklas Luhmann: a improbabilidade da comunicação e os meios simbolicamente generalizados. In: Conexão - Comunicação e Cultura, UCS, Caxias do Sul - v. 12, n. 24, jul./dez. $2013 . \quad$ Disponível em: http://www.ucs.br/etc/revistas/index.php/conexao/article/viewFile/2365/1534. Acessado em 10 jul. 2015.

RODRIGUES, Léo Peixoto. Sistemas auto-referentes, autopoiéticos: noçõeschave para a compreensão de Niklas Luhmann. Disponível em: http://pensamentoplural.ufpel.edu.br/edicoes/03/05.pdf. Acessado em: 10 jul. 2015.

Submetido em: Janeiro/2016

Aprovado em: Abril/2016 